\title{
Perception of Local Participants during Samosir Ultra Marathon 10 Kilometers Championship
}

\author{
Joen Parningotan Purba ", Widiastuti, Iman Sulaiman, Milda Vinna Br Payung, \\ Yafi Velyan Mahyudi
}

Department of Physical Education, Universitas Negeri Jakarta, Indonesia

Received July 3, 2021; Revised August 20, 2021; Accepted September 22, 2021

\begin{abstract}
Cite This Paper in the following Citation Styles
(a): [1] Joen Parningotan Purba, Widiastuti, Iman Sulaiman, Milda Vinna Br Payung, Yafi Velyan Mahyudi, "Perception of Local Participants during Samosir Ultra Marathon 10 Kilometers Championship, "International Journal of Human Movement and Sports Sciences, Vol. 9, No. 6, pp. 1118 - 1124, 2021. DOI: 10.13189/saj.2021.090606.
\end{abstract}

(b): Joen Parningotan Purba, Widiastuti, Iman Sulaiman, Milda Vinna Br Payung, Yafi Velyan Mahyudi (2021). Perception of Local Participants during Samosir Ultra Marathon 10 Kilometers Championship. International Journal of Human Movement and Sports Sciences, 9(6), 1118 - 1124. DOI: 10.13189/saj.2021.090606.

Copyright $@ 2021$ by authors, all rights reserved. Authors agree that this article remains permanently open access under the terms of the Creative Commons Attribution License 4.0 International License

\begin{abstract}
This study aims to determine the perception of local athletes participating in the Samosir Ultra Marathon based on ambience, achievement, escape, satisfaction and behavioral intention after participating in the championship. The championships that are followed can determine the athlete's perception of participating in this event the following year and can promote friends and family to take part in this championship. The research method used is mixed methods with a sample of 87 local athletes determined by purposive sampling. The results of this study indicate that Ambience gets a score of 885 with a percentage of $84.77 \%$, achievement score 931 with a percentage of $89.18 \%$, escape scores 1237 with a percentage of $88.86 \%$, satisfaction score 548 with a percentage of $83.91 \%$ and Behavioral Intention score 606 with a percentage of $87.07 \%$. According to them, the ambience and support from the spectators during the race was very good so that the athletes could achieve their goals by participating in the event. Athletes can also evaluate the results of the race well. All athletes can escape the routine of life and emotions for a while by participating in this event. They are also satisfied with their decision to participate in this event because it is only held once a year and is an international event. As many as $81.61 \%$ of the athletes said they wanted to participate in this event next year and wanted to recommend this championship to their friends and family. Ambience, achievement, and escape have a positive effect on satisfaction of athletes based on
\end{abstract}

their experience in participating in this championship, so they want to participate in next year and sports management must maintain its quality in organizing marathon events and be managed properly.

Keywords Athlete Perception, Ambience, Achievement, Escape, Satisfaction, Behavioral Intention

\section{Introduction}

Identification of the development of local athletes in participating marathon championships is very important to ensure athletes can reach their full potential and have an impact on other competitions. The are implications for coaches and sport psychologists who may appraise their professional responsibilities parallel to the case provided [1]. The perception of coaches and athletes is very important to evaluate the performance of athletes during competition. Perceptions of participants associated with the coaches' role and actual involvement in team hazing experiences, including taking a proactive stance against hazing and accepting hazing [2]. Coaches' perceptions of long-term potential can be biased by maturational variation in adolescent athletes in talented but late maturing athletes missing selection into development pathways [3]. 
Running is a popular sports discipline which can be performed over many distances. The schedule for the marathon championship is routine every year. The participation of local participants came from outside the province. Local and non-local participants evaluate their event experiences differently and provide practical implications for event organizers [4]. Organizing sports events in general has a contribution to the level of regional income and the surrounding population. The results show that this contribution is higher in those economies accounts for a higher share of gross domestic product (GDP) [5]. In addition, athlete achievement or top performance can only be known when an athlete participates in a championship because they can evaluate a long-term training program to participate in the next event. That demography plays an important role in the improvement of top performances [6]. That both training and anthropometry were independently associated with race performance [7]. the type and frequency of training, and the number of years running were the best predictors of running performance and success in the $10-\mathrm{km}$ distance [8].

Health problems with decreasing physical activity become a sedentary lifestyle for some people, which is followed by the results of previous research. The global health-related problems of decreasing physical activity, increasing sedentary lifestyles [9]. As long as the volume of physical activity is high, health-related fitness will be high as well, independent of the physical activity pattern or variability in intensities throughout the day [10]. Sport is one way to improve a person's quality of life. Numerous benefits of regular physical activity are considered, which helps maintain and improve the quality of life [11]. People will be more excited when doing sports with friends, trainers or family supported by a comfortable atmosphere so that exercise performance will increase. A Physical activity and counseling intervention delivered either in a group or individual format could reduce stress and burnout, and improve HRQoL of working [12]. It is related to the low hardy personality group, which means that they have less adaptation to the demands of the sports environment [13]. Adults described the importance of trust and the development of deep friendships through the activity more often [14].

There also remains much potential for sports administrators to harness the interests of non-local residents as consumers of sport. Sports may, for example, moderate the spatial travel patterns of international tourists who may be attracted to the entertainment and cultural values of live sport, much to the benefit of host cities. Investigation is warranted if athletes' perceptions of the talent development environment that they are involved in are related to their perceived level of achievement. The result from such a design could potentially generate knowledge about important factors in the talent development environment related to athletes' achievement and psychological functioning. The environment was positively associated with motivational outcomes [15]. Players perceiving their talent development environment as supporting and focusing on long-term development seem to be less stressed and experience higher well-being than other players [16].

Athletes' perceptions of the events held will also affect their satisfaction with the atmosphere, support from the audience and teammates, emotional and the achievements achieved during the event. Support for the expected effects of pre-competition anxiety, self-confidence, and idiosyncratic emotions on performance [17]. Those athletes who are well-peer mentored by a teammate perceive higher satisfaction levels with various aspects of their athletic experience and teammate support in enhancing the student-athletes subjective well-being [18] [19]. Athletes' perception of social support provided by coaches was positively correlated with their optimistic tendency and psychological well-being [20]. A moderate relationship was found between leadership and cohesion, and a close relationship was found between leadership and satisfaction [21]. Researchers argue that support from coaches or teammates has a positive influence on athletes and increases motivation and satisfaction when competing.

\section{Method}

This research uses mixed methods, which combine qualitative and quantitative data. The method used is a survey of athletes' perceptions of ambience, achievement, escape and satisfaction. Use of qualitative and quantitative viewpoints, data collection, analysis, inference techniques) for the broad purposes of breadth and depth of understanding and corroboration [22]. Local athletes from the provinces of DKI Jakarta, West Sumatra, North Sumatera and Aceh who took part in the running competition were used to become participants. The sample in this study was 87 athletes who participated in the Samosir Ultra Marathon 10 kilometers and 5 kilometers event. They were selected by purposive sampling by determining the criteria for local athletes participating in the competition. Athletes involved in this study are junior and senior categories (62 senior athletes in the 10 kilometers category and 25 junior athletes in the 5 kilometers category. The author determines himself the athletes who become participants according to the criteria to provide the required information. The research instrument was adopted from several previous studies. Ambience, achievement, escape, satisfaction and behavioral intentions were collected with questionnaires filled out by participants during the competition.

The data collection used were questionnaires, observations, and interviews with all samples to find out their perceptions after participating in this event. Three 
items for ambience, and two for satisfaction were based on the work of [23]. Three items for achievement and two items for behavioral intention were based on the works of [24]. Four items for the escape were based on the research of [25]. A four-point Likert scale ( $1=$ strongly disagree; 4 $=$ strongly agree) was used to assess the items.

Strengthen the results of the research, data analysis used triangulation from the results of questionnaires, observations and interviews. So that the results of this study will be more objective and the data obtained are theoretically valid. Triangulation of data analysis techniques and argue that such triangulation increases the reliability of the results [26]. The results obtained through a particular data analysis technique, for example, thematic analysis, are congruent with the results obtained by analyzing the same transcripts using a different technique, for example, correspondence analysis, it is reasonable to argue that the analysis and interpretation of the data are valid.

\section{Results}

Samosir Ultra Marathon is one of the running sports events located around Lake Toba. This event aims to promote public health through sporting events and can be attended by many participants. In addition, to increase visitors and to improve the achievements of national athletes. The implementation of this championship is expected to have a positive impact on the community around Lake Toba because of the large number of spectators so that athlete's satisfaction becomes a good experience while participating in the championship. The following will show the results of the research that has been done. The results show that the participants, in general, reported high levels of well-being and a positive perception of the ambience, achievement, escape, satisfaction and, behavioral intention in Table 1 .

Table 1. Questionnaire results per question item

\begin{tabular}{|c|c|c|c|}
\hline Items & Mean & Score & Percentage \\
\hline $\begin{array}{l}\text { Ambience } \\
\text { Support from spectators along the competition was great } \\
\text { All peripheral events parallel to the race are well planned } \\
\text { The atmosphere during the event is very support }\end{array}$ & $\begin{array}{l}3,30 \\
3,34 \\
3,53\end{array}$ & $\begin{array}{l}287 \\
291 \\
307\end{array}$ & $\begin{array}{l}82,47 \% \\
83,62 \% \\
88,22 \%\end{array}$ \\
\hline $\begin{array}{l}\text { Achievement } \\
\text { I could feel a sense of accomplishment through participating in the event } \\
\text { I could achieve my goal by participating in the event } \\
\text { I would evaluate the outcome of my race participation favorably }\end{array}$ & $\begin{array}{l}3,49 \\
3,56 \\
3,64\end{array}$ & $\begin{array}{l}304 \\
310 \\
317\end{array}$ & $\begin{array}{l}87,36 \% \\
89,08 \% \\
91,09 \%\end{array}$ \\
\hline $\begin{array}{l}\text { Escape } \\
\text { I can get distracted from my normal life for a while by participating in the event } \\
\text { I can forget my worries by participating in the event } \\
\text { I can get away from the routine of everyday life by participating in the event } \\
\text { I can get emotionally refreshed through participating in the event }\end{array}$ & $\begin{array}{l}3,49 \\
3,54 \\
3,54 \\
3,64\end{array}$ & $\begin{array}{l}304 \\
308 \\
308 \\
317\end{array}$ & $\begin{array}{l}87,36 \% \\
88,51 \% \\
88,51 \% \\
91,09 \%\end{array}$ \\
\hline $\begin{array}{l}\text { Satisfaction } \\
\text { Overall, I was satisfied with my decision to participate in the event } \\
\text { Participating in the event was the right choice for me }\end{array}$ & $\begin{array}{l}3,45 \\
3,26\end{array}$ & $\begin{array}{l}300 \\
284\end{array}$ & $\begin{array}{l}86,21 \% \\
81,61 \%\end{array}$ \\
\hline $\begin{array}{l}\text { Behavioral Intention } \\
\text { I would like to participate in the event next year } \\
\text { I would like to recommend the event to my friends and family }\end{array}$ & $\begin{array}{l}3,40 \\
3,56\end{array}$ & $\begin{array}{l}296 \\
310 \\
\end{array}$ & $\begin{array}{l}85,06 \% \\
89,08 \% \\
\end{array}$ \\
\hline
\end{tabular}

Table 2. Results of the Ambience, Achievement, Escape, Satisfaction and Behavioral Intention questionnaires

\begin{tabular}{cccccc}
\hline & Ambience & Achievement & Escape & Satisfaction & $\begin{array}{c}\text { Behavioral } \\
\text { Intention }\end{array}$ \\
\cline { 2 - 6 } Score & 885 & 931 & 1237 & 584 & 606 \\
Mean & 3,391 & 3,567 & 3,555 & 3,356 & 3,483 \\
SD & 0,489 & 0,496 & 0,498 & 0,480 & 0,501 \\
Score total & 1044 & 1044 & 1392 & 696 & 696 \\
Percentage & $84,77 \%$ & $89,18 \%$ & $88,86 \%$ & $83,91 \%$ & $87,07 \%$ \\
\hline
\end{tabular}


The questionnaire that was filled out by athletes in the senior and junior categories (5 kilometers and 10 kilometers) obtained data based on Table 1. ambience: support from spectators along the competition was great with a percentage $82,47 \%$. All peripheral events parallel to the race are well planned is $83,62 \%$. The atmosphere during the event is very supportive is $88,22 \%$. Achievement: i could feel a sense of accomplishment through participating in the event is $87,36 \%$. I could achieve my goal by participating in the event is $89,08 \%$. I would evaluate the outcome of my race participation favorably is $91,09 \%$. Escape: I can get distracted from my normal life for a while by participating in the event is $87,36 \%$. I can forget my worries by participating in the event $88,51 \%$. I can get away from the routine of everyday life by participating in the event $88,51 \%$. I can get emotionally refreshed through participating in the event at $91,09 \%$. Satisfaction: Overall, I was satisfied with my decision to participate in the event at $86,21 \%$. Participating in the event was the right choice for me $81,61 \%$. Behavioral intention: I would like to participate in the event next year at $85,06 \%$. I would like to recommend the event to my friends and family $89,08 \%$.

Based on the results from Table 1 , it can be seen that according to the athletes who participated in the Samosir Ultra Marathon, the support from the audience throughout the match was very good, all events could go according to plan and the natural atmosphere of Lake Toba was still natural so it was very supportive and had a positive impact during the match. Athletes can also feel their achievements while participating in this event so that it becomes an evaluation material for the achievements that have been made in the match. Those who participate in this event can get away from their training routines and daily life and can release anxiety during the match. In addition, they can also feel satisfied with his decision to participate in this event well.

"Ambience in Lake Toba is indeed suitable and supportive for an event like this because it has beautiful nature, fresh air and the water does not flow fast. The achievement that I feel while participating in this event is also very good because it can be used as a reference for achievement at the national level" (informant 31).

"In my opinion, this competition can have a positive effect because it can change your lifestyle by exercising regularly every day before participating in this race" (informant 3).

"In the 10 kilometers race category, there was a lot of support from participants to keep finishing the race, and that gave me motivation during the race" (informant 44).

"I think that this event was held appropriately because it has a positive impact on measuring achievement during the training that has been carried out. I will participate in this event next year because I can achieve the best performance here" (informant 7).

Based on table 2, it can be seen that the athletes overall stated the ambience is in the very good category because the atmosphere and support during the event could provide extrinsic enthusiasm and motivation. In the variable achievement, athletes who get 1st, 2nd and 3rd podiums state that they can evaluate the achievements achieved. All athletes stated that they escaped in the very good category, they were able to let go of the routines of daily life. Satisfaction is very good because they are satisfied with participating in this competition because of the ambience and support from friends during the race. The behavioral intention in the very good category so that they have the desire to take part in the competition the following year. Overall, ambience, achievement, escape, satisfaction and behavioral intention have a positive effect on athletes while participating in the event.

From the results of this study, sports and tourism management at the Samosir Ultra Marathon on Lake Toba can help event organizers to prepare a good marathon event that can be followed by participants from outside the country. Participants' satisfaction related to ambience, achievement and escape gave a positive perception of participating in this next event. Therefore, sports management must maintain its quality in organizing marathon events and be managed properly in order to have a positive impact on participants and the surrounding community.

\section{Discussion}

The Samosir Ultra Marathon Championship which is held in the Horas Samosir Fiesta program is an annual agenda. Many athletes took part in this event, based on the data obtained there were 1125 athletes (496 participants for 5 kilometers, 378 participants for 10 kilometers, 153 participants for 25 kilometers and 98 participants for 50 kilometers. This year's event is considered different from the last year due to an increase in The number of participants which means that the satisfaction and behavioral intention felt by athletes and coaches is very good while participating in this event. Satisfaction had an extensively positive effect on behavioral intention [4]. Perceived coach-created task climate was positively related to perceived cohesion and players' satisfaction with their participation within their team [27]. Participants have the capability of differentiating between event and destination satisfaction when evaluating their future intentions [28]. Athletes' satisfaction can also be seen when they upload pictures or videos on social media while participating in this event.

The support is given by the spectators and teammates during the match also affects the athlete's achievement. 
Teammate support had a positive influence on subjective well-being through positive emotion [19]. It was proven that during the race, the voices of the spectators were very busy supporting and watching the athletes competing so that the participants thought that their spirit and motivation would also increase. That motivation directly affects satisfaction and indirectly affects loyalty, whereas satisfaction directly affects attendee loyalty at aboriginal festivals [29]. Positive correlations were observed among social support provided by coaches, optimism, and psychological well-being [20]. Teachers have a good perception, which is indicated by a dominant good result, according to them, by making Lake Sipin area, will make students motivated to become rowing athletes [30]. Support for an active sport tourism taxonomy and framework based on the mode of experience and achievement orientation [31].

An important question is related to the athlete's perception and actions regarding his decision to enter the race and whether the decision is temporary or in the next few days. During the race, it can be said that athletes can change their daily activities temporarily and forgotten for a while to achieve their goals. The results show perception of Success Questionnaire to be a reliable and valid instrument to measure achievement goal orientations in sport [32]. Athletes can also evaluate themselves from the results obtained during this competition. Achievement goals and sport motivation with the high mental toughness group favoring both mastery- and performance-approach goals and self-determined as well as extrinsic motivational [33]. The three goals have similar effects on the performance and enjoyment of a golf-putting task [34]. The training process that becomes a routine during the training program becomes a guide for the success of athletes. Skill performance obtained is also a factor in the success of athletes to achieve goals in this competition. The relationships between the covert and overt behaviors are related to skilled motor performance [35].

The athlete's decision to take part in this competition is the right decision because this is an annual competition agenda on Lake Toba. There are many marathon competitions held by the government but do not display a natural atmosphere that is still natural. Athletes feel a different atmosphere and environment during the race. Ambience in the athlete's opinion contributes to the achievement of the goal of participating in this event. Ambience also affects escape. In the opinion of athletes they can forget daily activities and eliminate worries while participating in the championship do not have fun. These three factors affect the satisfaction of athletes and help athletes make the right choice while participating in this event. Surf camp experiences connected to surf lessons, natural resources of surf spots, human resources in surf camps and recommendations after experiences [36]. The activities performed by the tourists have an impact on their perceived winter sports experience [37]. The athlete's experience during participation also makes the recommendation for ambience at Lake Toba. The quality of the event experience can be a focus for event managers aiming to achieve social marketing goals related to positive psychology from the event participation [38], and the interaction effect between Coach training and the coaching experience. Implications are given for coach education programs are training coaches to explicitly teach life skills through sport [39].

\section{Conclusion}

Event organizers must improve the athlete's experience of the atmosphere, achievement, and escape from the event as these aspects can contribute to participant satisfaction. Special attention must be paid to the athletes in the junior category who enter the 5 kilometers category in order to be experienced. In this case, ambience, achievement, and escape must satisfy runners so that they can change the behavior of participants in a better direction. Based on research data can be concluded that ambience, achievement and escape have a positive effect on satisfaction athletes based on their experience in participating in this event, so they want to participate in the event the following year because they feel it can have a good influence on the desire to exercise. Ambience-related items are used to evaluate the physical environment quality, and a positive relationship between the physical environment quality and satisfaction has not been identified properly. Therefore, it is hoped that there will be further research that discusses whether environment quality is related to athlete satisfaction and achievement.

\section{Acknowledgments}

Thanks to all participants in this research. As well as all event organizers who have helped and given permission to conduct research.

\section{REFERENCES}

[1] C. Breakey, M. Jones, C.-T. Cunningham, and N. Holt, "Female Athletes' Perceptions of a Coach's Speeches," Int. J. Sports Sci. Coach., vol. 4, no. 4, pp. 489-504, Dec. 2009, doi: 10.1260/174795409790291376.

[2] C. Kowalski and J. Waldron, "Looking the other way: Athletes' perceptions of coaches' responses to hazing," Int. J. Sport. Sci. Coach., vol. 5, no. 1, pp. 87-100, Mar. 2010, doi: 10.1260/1747-9541.5.1.87.

[3] A. J. Cripps, L. S. Hopper, and C. Joyce, "Coaches' perceptions of long-term potential are biased by 
maturational variation," Int. J. Sport. Sci. Coach., vol. 11, no. 4, pp. 478-481, Aug. 2016, doi: 10.1177/17479541166 55054 .

[4] B. An, M. Harada, and S. Sato, "Service quality, satisfaction, and behavioral intention in a triathlon event: the different experiences between local and non-local participants," $J$. Sport Tour., vol. 24, no. 2, pp. 127-142, Apr. 2020, doi: $10.1080 / 14775085.2020 .1773296$.

[5] S. H. Ivanov and C. Webster, "Tourism's contribution to economic growth: A global analysis for the first decade of the millennium," Tour. Econ., 2013, doi: 10.5367/te.2013.0211

[6] A. Marc et al., "Marathon progress: demography, morphology and environment," J. Sports Sci., vol. 32, no. 6, pp. 524-532, 2014, doi: 10.1080/02640414.2013.835436.

[7] B. Knechtle, P. Knechtle, T. Rosemann, and O. Senn, "What is associated with race performance in male $100-\mathrm{km}$ ultra-marathoners anthropometry, training or marathon best time?," J. Sports Sci., vol. 29, no. 6, pp. 571-577, Mar. 2011, doi: $10.1080 / 02640414.2010 .541272$.

[8] T. G. Martin, R. W. Pata, J. D'Addario, L. Yuknis, R. Kingston, and R. Feinn, "Impact of age on haematological markers pre- and post-marathon running," J. Sports Sci., vol. 33, no. 19, pp. 1988-1997, 2015, doi: 10.1080/02640414.2015.1024712.

[9] S. Kokko, J. Villberg, and L. Kannas, "Health promotion in sport coaching: Coaches and young male athletes' evaluations on the health promotion activity of coaches," Int. J. Sport. Sci. Coach., vol. 10, no. 2-3, pp. 339-352, Jun. 2015, doi: 10.1260/1747-9541.10.2-3.339.

[10] [10] S. Knaeps, J. G. Bourgois, R. Charlier, E. Mertens, and J. Lefevre, "Associations between physical activity and health-related fitness-volume versus pattern," J. Sports Sci., vol. 35, no. 6, pp. 539-546, Mar. 2017, doi: 10.1080/02640414.2016.1178393.

[11] A. Almonacid-Fierro, R. Vargas-Vitoria, M. Almonacid, and M. Martínez, "Perception on the quality of life of elderly people during COVID-19 pandemic in Chile," Int. J. Hum. Mov. Sport. Sci., vol. 9, no. 3, pp. 473-479, 2021, doi: 10.13189/saj.2021.090312.

[12] H. Wang et al., "of Physical Activity and Counselling Interventions on Health Outcomes among Working Women in Shanghai," J. Sport. Sci. Med., vol. 20, no. 1, pp. 77-85, 2021, doi: $10.52082 /$ jssm.2021.77.

[13] H. González-García and A. Pelegrín, "Influence of Perceived Parental Education Styles on Hardy Personality in Sport," 2020. Accessed: Jun. 20, 2021. [Online]. Available: http://www.jssm.org.

[14] A. Frühauf, J. Zenzmaier, and M. Kopp, "Age Matter? A Qualitative Comparison of Motives and Aspects of Risk in Adolescent and Adult Freeriders," 2020. Accessed: Jun. 20, 2021. [Online]. Available: http://www.jssm.org.

[15] C. Li, R. Martindale, Y. Wu, and G. Si, "Psychometric properties of the Talent Development Environment Questionnaire with Chinese talented athletes," J. Sports Sci., vol. 36, no. 1, pp. 79-85, Jan. 2018, doi: 10.1080/02640414.2017.1282619.
[16] A. Ivarsson, A. Stenling, J. Fallby, U. Johnson, E. Borg, and G. Johansson, "The predictive ability of the talent development environment on youth elite football players' well-being: A person-centered approach," Psychol. Sport Exerc., vol. 16, no. P1, pp. 15-23, Jan. 2015, doi: 10.1016/j.psychsport.2014.09.006.

[17] C. Robazza, M. Pellizzari, M. Bertollo, and Y. L. Hanin, "Functional impact of emotions on athletic performance: Comparing the IZOF model and the directional perception approach," J. Sports Sci., vol. 26, no. 10, pp. 1033-1047, Aug. 2008, doi: 10.1080/02640410802027352.

[18] M. D. Hoffmann and T. M. Loughead, "A comparison of well-peer mentored and non-peer mentored athletes' perceptions of satisfaction," J. Sports Sci., vol. 34, no. 5, pp. 450-458, Mar. 2016, doi: 10.1080/02640414.2015.105751 7.

[19] H. Cho, H. Yi Tan, and E. Lee, "Importance of perceived teammate support as a predictor of student-athletes' positive emotions and subjective well-being," Int. J. Sport. Sci. Coach., vol. 15, no. 3, pp. 364-374, Jun. 2020, doi: $10.1177 / 1747954120919720$.

[20] T. W. Cnen, Y. C. Chiu, and Y. Hsu, "Perception of social support provided by coaches, optimism/pessimism, and psychological well-being: Gender differences and mediating effect models," Int. J. Sport. Sci. Coach., vol. 16, no. 2, pp. 272-280, Apr. 2021, doi: 10.1177/17479541209 68649 .

[21] H.-D. Kim and A. B. Cruz, "The influence of coaches' leadership styles on athletes' satisfaction and team cohesion: A meta-analytic approach,", Nov. 2016, DOI: $10.1177 / 1747954116676117$.

[22] J. Schoonenboom and R. B. Johnson, "How to Construct a Mixed Methods Research Design," Kolner Z. Soz. Sozpsychol., vol. 69, pp. 107-131, 2017, doi: 10.1007/s11577-017-0454-1.

[23] N. D. Theodorakis, K. (Kiki) Kaplanidou, and I. Karabaxoglou, "Effect of Event Service Quality and Satisfaction on Happiness Among Runners of a Recurring Sport Event," Leis. Sci., vol. 37, no. 1, pp. 87-107, Jan. 2015, doi: 10.1080/01490400.2014.938846.

[24] J. Du, J. S. Jordan, and D. C. Funk, "Managing mass sport participation: Adding a personal performance perspective to remodel antecedents and consequences of participant sport event satisfaction," J. Sport Manag., vol. 29, no. 6, pp. 688704, Nov. 2015, doi: 10.1123/JSM.2014-0225.

[25] D. C. Funk, K. Toohey, and T. Bruun, "International Sport Event Participation: Prior Sport Involvement; Destination Image; and Travel Motives," Eur. Sport Manag. Q., vol. 7, no. 3, pp. 227-248, Sep. 2007, doi: 10.1080/16184740701 511011 .

[26] M. A. Lauri, "Triangulation of Data Analysis Techniques," Oct. 2011. Accessed: Jun. 06, 2021. [Online]. Available: http://www.psych.lse.ac.uk/psr/.

[27] T. García-Calvo, F. M. Leo, I. Gonzalez-Ponce, P. A. Sánchez-Miguel, A. Mouratidis, and N. Ntoumanis, "Perceived coach-created and peer-created motivational climates and their associations with team cohesion and athlete satisfaction: Evidence from a longitudinal study," $J$. 
Sports Sci., vol. 32, no. 18, pp. 1738-1750, 2014, doi: 10.1080/02640414.2014.918641.

[28] D. Plunkett and T. J. Brooks, "Examining the relationship between satisfaction, intentions, and post-trip communication behaviour of active event sport tourists," $J$. Sport Tour., vol. 22, no. 4, pp. 303-313, Oct. 2018, doi: 10.1080/14775085.2018.1532806.

[29] T. H. Lee and F. Y. Hsu, "Examining How Attending Motivation and Satisfaction Affects the Loyalty for Attendees at Aboriginal Festivals," Int. J. Tour. Res., vol. 15, no. 1, pp. 18-34, Jan. 2013, doi: 10.1002/jtr.867.

[30] U. Nugraha, M. Asmawi, H. Humaid, and F. Dlis, "Sports teacher perception about lake sipin sport tourism area in Jambi city," Int. J. Hum. Mov. Sport. Sci., vol. 8, no. 4, pp. 103-109, 2020, doi: 10.13189/saj.2020.080401.

[31] G. J. Walker, T. Hinch, and J. Higham, “Athletes as tourists: The roles of mode of experience and achievement orientation," J. Sport Tour., vol. 15, no. 4, pp. 287-305, Nov. 2010, doi: 10.1080/14775085.2010.533919.

[32] G. C. Roberts, D. C. Treasure, and G. Balague, "Achievement goals in sport: The development and validation of the perception of success questionnaire," $J$. Sports Sci., vol. 16, no. 4, pp. 337-347, 2013, doi: 10.1080/02640419808559362.

[33] D. F. Gucciardi, "Mental toughness profiles and their relations with achievement goals and sport motivation in adolescent Australian footballers," J. Sports Sci., vol. 28, no.
6, pp. 615-625, Apr. 2015, doi: 10.1080/02640410903582 792.

[34] M. Kavussanu, R. L. Morris, and C. Ring, "The effects of achievement goals on performance, enjoyment, and practice of a novel motor task," J. Sports Sci., vol. 27, no. 12, pp. 1281-1292, Oct. 2012, doi: 10.1080/02640410903229287.

[35] G. Tenenbaum and J. Summers, "Perception-action relationships in strategic-type settings: Covert and overt processes," Journal of Sports Sciences, vol. 15, no. 6 . Taylor \& Francis, pp. 559-572, Dec. 2013, doi: 10.1080/026404197366994.

[36] A. Brochado, O. Stoleriu, and C. Lupu, "Surf camp experiences," J. Sport Tour., vol. 22, no. 1, pp. 21-41, Jan. 2018, doi: 10.1080/14775085.2018.1430609.

[37] K. Hallmann, S. Feiler, S. Müller, and C. Breuer, "The interrelationship between sport activities and the perceived winter sport experience," J. Sport Tour., vol. 17, no. 2, pp. 145-163, May 2012, doi: 10.1080/14775085.2012.729905.

[38] N. D. Theodorakis, K. (Kiki) Kaplanidou, and I. Karabaxoglou, "Effect of Event Service Quality and Satisfaction on Happiness Among Runners of a Recurring Sport Event," Leis. Sci., vol. 37, no. 1, pp. 87-107, Jan. 2015, doi: 10.1080/01490400.2014.938846.

[39] S. Kramers, S. Turgeon, C. Bean, C. Sabourin, and M. Camiré, "Examining the roles of coaching experience and coach training on coaches' perceived life skills teaching," Int. J. Sport. Sci. Coach., vol. 15, no. 4, pp. 576-583, Aug. 2020, doi: 10.1177/1747954120922367. 